\title{
Breast-feeding and postpartum weight retention: a systematic review and meta-analysis
}

\author{
Xiujie He, Meng Zhu, Chuanlai Hu*, Xingyong Tao, Yingchun Li, Qiuwei Wang and \\ Yue Liu \\ Division of Nutrition and Food Hygiene, School of Public Health, Anhui Medical University, 81 Mei Shan Road, \\ Hefei 230032, Anhui, People's Republic of China
}

Submitted 2 November 2013: Final revision received 13 November 2014: Accepted 4 February 2015: First published online 21 April 2015

\begin{abstract}
Objective: Weight gained during pregnancy and postpartum weight retention might contribute to obesity in women of childbearing age. Whether breast-feeding (BF) may decrease postpartum weight retention (PPWR) is still controversial. The purpose of our systematic review and meta-analysis was to investigate the relationship between BF and PPWR.

Design: Three databases were systematically reviewed and the reference lists of relevant articles were checked. Meta-analysis was performed to quantify the pooled standardized mean differences (SMD) of BF on PPWR by using a randomeffect model. Heterogeneity was tested using the $\chi^{2}$ test and $I^{2}$ statistics. Publication bias was estimated from Egger's test (linear regression method) or Begg's test (rank correlation method).

Results: Among 349 search hits, eleven studies met the inclusion criteria for the meta-analysis. Seven studies were conducted in the USA, one in Brazil, one in France, one in Georgia and one in Croatia. Compared with formula-feeding, BF for 3 to $\leq 6$ months seemed to have a negative influence on PPWR and if BF continued for $>6$ months had little or no influence on PPWR. In a subgroup meta-analysis, the results did not change substantially after the analysis had been classified by available confounding factors. There was no indication of a publication bias from the result of either Egger's test or Begg's test.

Conclusions: Although the available evidence held belief that BF decreases PPWR, more robust studies are needed to reliably assess the impact of patterns and duration of BF on PPWR.
\end{abstract}

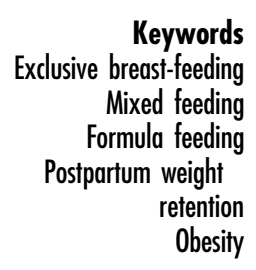

Obesity is a growing problem on a global scale among populations in both developing and affluent countries. Pregnancy and the postpartum period is a time of increased maternal vulnerability to weight gain and body composition changes. Although many women have a desire to return to their pre-pregnancy weight after childbirth $^{(1)}$, very few achieve this goal ${ }^{(2-4)}$. Excessive postpartum weight retention (PPWR) can contribute to maternal long-term obesity and be associated with CVD, hypertension, diabetes and degenerative joint disease ${ }^{(5,6)}$.

Although breast-feeding (BF) is associated with health benefits for both mother and baby ${ }^{(7,8)}$, its role in postpartum weight management remains unclear. Theoretically, BF should decrease PPWR during the postpartum period as it utilizes energy, but in fact some women may gain weight during lactation ${ }^{(9)}$. Because of the hypothesized fat mobilization during lactation, BF is often considered as a factor that facilitates postpartum weight loss. However, given the many factors that may influence postpartum weight change, such as socio-economic status ${ }^{(10)}$, ethnicity $^{(11,12)}$, pre-pregnancy weight ${ }^{(13-15)}$, parity ${ }^{(16)}$, gestational weight gain (GWG) ${ }^{(16)}$ and lifestyle ${ }^{(17,18)}$, the weightreducing effects of postpartum lactation remain in dispute.

Some studies have shown that BF significantly reduces PPWR ${ }^{(19-26)}$. The energy needs of lactating women are about $2090 \mathrm{~kJ} / \mathrm{d}$ greater than those of non-lactating mothers ${ }^{(13)}$, which reflects the fact that producing more milk requires additional energy and, in the absence of restriction of food intake or changes in physical activity, should lead to greater weight loss. Other studies have 
reported no effect of $\mathrm{BF}$ on maternal anthropometry and body composition ${ }^{(27-30)}$. These differences may be due to the intensity and duration of BF, study population (source, size, location, loss to follow-up), how weight and weight retention were assessed, how BF was assessed and statistical methods.

To our knowledge, there have not been any quantitative attempts to further explore the possible BF-PPWR association. Given that obesity is considered to be a public health problem, a more clear understanding the role of $\mathrm{BF}$ in weight management is very necessary. Therefore, we carried out a systematic review and meta-analysis aiming to help clarify the association between BF and PPWR.

\section{Methods}

\section{Search strategy and study selection}

We performed a detailed search for studies that examined the association between BF and PPWR. A search of the literature was made by using Medline (PubMed, http:// www.bdpubmed.com/), EMBASE (http://www.embase. com/) and Cochrane library (http://www.thecochrane library.com/) from their inception to October 2014 to identify relevant articles. References in key studies were reviewed to identify additional studies not indexed by Medline, EMBASE or Cochrane library.

We used the following search terms: (('Breastfeeding' OR 'formula feeding' OR 'bottle-feeding' OR 'lactation' OR 'non-lactation') AND ('weight loss' OR 'weight change' OR 'weight retention' OR 'body composition') AND ('postpartum' OR 'parturition' OR 'postnatal period' OR 'childbirth') AND ('mother' OR 'women')).

Randomized controlled trials (RCT) and cohort studies were included, irrespective of sample size or follow-up duration. In addition, a hand search of reference lists of relevant and related articles was made to ensure a complete collection. The first step was a systematic review of all eligible studies on healthy women, the studies had to be published in English and report the association between BF and PPWR; in the second step a meta-analysis was conducted. Studies included in the meta-analysis had to meet the following inclusion criteria: (i) RCT or cohort study; (ii) examine infant feeding method in relation to the outcome; (iii) have data on weight change or weight retention; (iv) report both mean and standard deviation; (v) measurement of weight, rather than self-reported; and (vi) include BF (exclusive breast-feeding (EBF) or mixed breast-feeding (MF)) and formula-feeding (FF) groups. BF practices were defined as: (i) $\mathrm{EBF}$, when the child received no water, tea, juice or food; (ii) MF, when the child received human milk, water, tea, juice but no food; and (iii) FF, when the child was not breast-fed.

\section{Screening and data-extraction form}

All search hits were exported to Endnote X4 (Thomson Reuters), which was used to organize the references and eliminate duplicates. Initially, two investigators (X.T. and Y. Li) independently screened the articles identified in the searches according to the predetermined criteria in order to select potentially relevant citations based on titles and abstracts; potential disagreements were resolved through consensus. For articles with relevant citations or with titles/ abstracts that were not sufficient for deciding on inclusion criteria, the full-text articles were retrieved and evaluated. The following characteristics were extracted from the articles: (i) author; (ii) country; (iii) time period; (iv) sample size; (v) whether or not $\mathrm{BF}$ and weight retention were variables of interest; (vi) BF intensity and duration; and (vii) adjustment for potential confounding factors.

\section{Assessment of study quality}

Study quality was assessed based on: (i) follow-up rate (1 point for follow-up rate $\geq 75 \%$ ); (ii) clear definition of exposure and outcome about BF and PPWR (if definition or outcome was reported, then 1 point was awarded); and (iii) inclusion and exclusion criteria (if criteria were reported, then 1 point was assigned) ${ }^{(31)}$. Thus, the potential maximum score was 6 points; a high-quality study was defined as a study with $\geq 5$ points. Two reviewers (X.T. and Y. Li) evaluated the quality of each study. A third reviewer (Q.W.) was designated to make a final decision if the initial two reviewers were unable to reach consensus.

\section{Statistical analysis}

We used the mean differences in weight loss of breastfeeders minus that of formula-feeders for meta-analysis. These differences were used to take account of the time dependency of weight change after pregnancy, which means that the effect variable is standardized mean difference (SMD). The pooled SMD and corresponding 95\% confidence intervals were calculated by using the inverse variances $\operatorname{method}^{(32,33)}$. We examined heterogeneity in results across studies by using the $\chi^{2}$ test and $I^{2}$ statistics $^{(33)}$. The null hypothesis that the studies are homogeneous was rejected if the $P$ value for heterogeneity was $<0 \cdot 10$ or $I^{2}$ was $>50 \%$. When substantial heterogeneity was detected, the summary estimate on the basis of the random-effects model (using the method of DerSimonian and Laird ${ }^{(32)}$ ) was presented. Otherwise, the pooled estimate that was based on the fixed-effects model (using the inverse variance method $^{(34)}$ ) was presented. Subgroup analyses were carried out by study design (RCT $v$. cohort studies), study quality ( $\geq 5$ points $v .<5$ points), number of confounding factors adjusted for $(<6 v . \geq 6)$ and study population (Americans $v$. non-Americans). We conducted a sensitivity analysis by excluding each study one by one and recalculating the combined estimates on the remaining studies to assess the effect of individual studies on the pooled result. We used Egger's test (linear regression method) ${ }^{(35)}$ and Begg's test (rank correlation method) ${ }^{(36)}$ to evaluate potential publication bias. Meta-analysis was performed with the statistical software package Stata/SE version 9. 


\section{Results}

\section{Identification of studies}

The applied search strategy yielded 349 potentially relevant publications in Medline, EMBASE and Cochrane library. No additional articles were found in the citations of the relevant studies by manual search. The evaluation of the 349 publications is shown in Fig. 1.

\section{Results of the systematic review}

In total, twenty-six studies met the inclusion criteria of the systematic review; fifteen of them were not eligible for the meta-analysis ${ }^{(19,20,22,28,37-47)}$ because they did not meet the inclusion criteria of the meta-analysis (see online supplementary material, Table S1). Most of the studies excluded from the meta-analysis had no control group $^{(19,22,37,38,41,43,45)}$. Although six of these thirteen studies had both BF and the control group, they still did not meet the inclusion criteria $(20,28,39,40,42,44)$. The study by Cohen et al. ${ }^{(39)}$ was a cross-sectional study, while the study by Mok et $a l .{ }^{(20)}$ was a case-control study. The cohort studies by Janney et $a l .{ }^{(40)}$ and Ota et $a l .{ }^{(44)}$ did not report the data of weight change, whereas the studies of Gigante et al. ${ }^{(42)}$ and Walker et $a l{ }^{(28)}$ did not report the standard deviation of the data. Nine of thirteen studies showed a protective effect of BF against PPWR ${ }^{(19,20,22,37,39-41,43,45)}$, whereas the other four studies failed to achieve significance ${ }^{(28,38,42,44)}$. In addition, another two studies ${ }^{(46,47)}$ were excluded because weight was not measured. Reasons for exclusion from the metaanalysis are shown in Table S1.

\section{Results of the meta-analysis}

Study characteristics and quality assessment

Eleven studies were eligible for the meta-analysis comprising more than 37000 women included in the final analysis $^{(15,48-57)}$. Table 1 shows characteristics of these studies and potential confounders, for which adjustment was made.

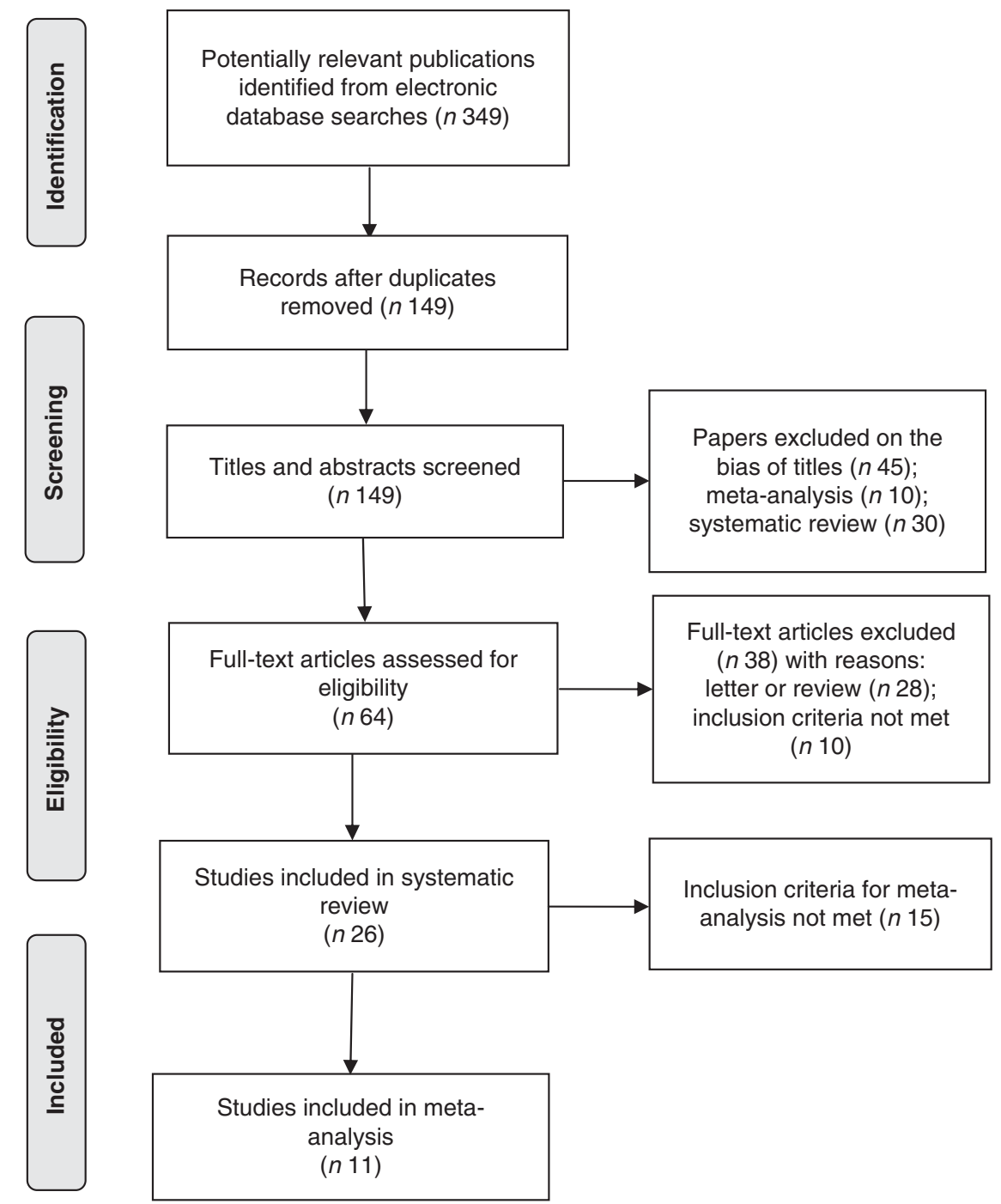

Fig. 1 Flow diagram of article selection according to PRISMA (Preferred Reporting Items for Systematic Reviews) guidelines 


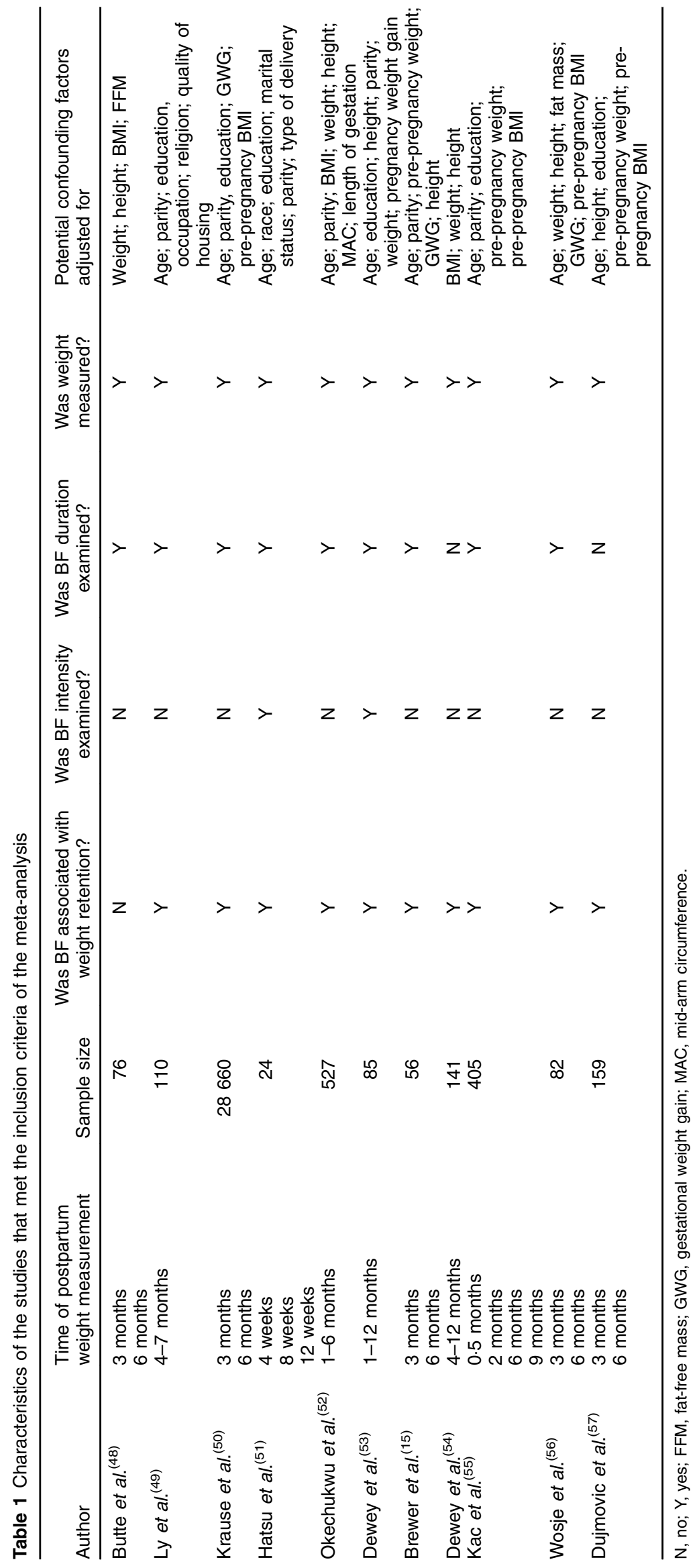


Seven studies were conducted in the USA, one in Brazil, one in France, one in Georgia and one in Croatia. Most individual studies were matched or adjusted for a wide range of potential confounders, including age, prepregnancy weight, pre-pregnancy BMI, education and parity. The results of individual studies are presented in the online supplementary material, Table S2. For the metaanalysis, we generated four categories covering similar postpartum time periods (see online supplementary material, Table S3).

As a whole, the methodological quality of the included trials was acceptable (see online supplementary material, Table S4). Study design and inclusion and exclusion criteria were mostly well recorded. An explicit definition for PPWR was reported in eleven articles. Nine of eleven studies had follow-up rates of $75 \%$ or more. In cohort studies and in the RCT, the percentage of women lost to follow-up ranged from 0 to $10 \%$. Bias in weight measurement was unlikely in eleven studies.

\section{Overall analyses}

The homogeneity hypothesis was rejected by $\chi^{2}$ test $\left(P<0.05, I^{2}=96.9 \%\right)$, thus we selected the random-effect model. There was non-significant effect $(-0.09 \mathrm{~kg} ; 95 \% \mathrm{CI}$ $-0.76,0.58 \mathrm{~kg}$ ) at 1 to $\leq 3$ months postpartum (see online supplementary material, Fig. S1). Compared with formulafeeders, breast-feeders lost $0.87 \mathrm{~kg}$ (95\% CI $0.57,1.17 \mathrm{~kg}$ ) more weight (Fig. 2). In addition, breast-feeders lost $0.37 \mathrm{~kg}$ more weight $(95 \%$ CI $0 \cdot 14,0.61 \mathrm{~kg})$ than formula-feeders at
9 to $\leq 12$ months postpartum (see online supplementary material, Fig. S3). This association was non-significant at 6-_9 months postpartum (0.21 kg; $95 \% \mathrm{CI}-0.42,0.83 \mathrm{~kg}$; online supplementary material, Fig. S2). There was no indication of a publication bias from the result of either Egger's test $(P=0.635)$ or Begg's test $(P=0.635)$.

\section{Subgroup and sensitivity analyses}

The effects of BF on PPWR in subgroup meta-analyses are shown in Table 2 . When stratified by study design, the analysis of RCT yielded an SMD of $0.57 \mathrm{~kg}$ (95\% CI 0.19 , $0.94 \mathrm{~kg}$ ), whereas the analysis on cohort studies yielded an SMD of $1.18 \mathrm{~kg}(95 \% \mathrm{CI} 0.74,1.62 \mathrm{~kg})$. In addition, the results did not change substantially after the analyses were stratified by some confounding factors (quality of studies, number of confounding factors adjusted for and study population).

In sensitivity analyses, we recalculated the combined results by excluding one study per iteration. The eleven study-specific SMD ranged from a low of $0.57 \mathrm{~kg}$ ( $95 \% \mathrm{CI}$ $0 \cdot 19,0.94 \mathrm{~kg})$ to a high of $1.27 \mathrm{~kg}(95 \%$ CI $0 \cdot 37,2 \cdot 17 \mathrm{~kg})$ and were similar without great fluctuation.

\section{Discussion}

A total of twenty-six epidemiological studies that consisted of three RCT and twenty-three cohort studies were included and eleven studies met the inclusion criteria of the meta-analysis. Seven studies were conducted in the USA,

\begin{tabular}{|c|c|c|}
\hline Study ID & SMD $(95 \% \mathrm{Cl})$ & Weight $(\%$ \\
\hline EBF & & \\
\hline$\overline{\text { Butte et al. }}{ }^{(48)}$ & $0.64(0.13,1.14)$ & 5.72 \\
\hline Ly et al. ${ }^{(49)}$ & $0.81(0.55,1.08)$ & $6 \cdot 46$ \\
\hline Krause et al. ${ }^{(50)}$ & $1.63(1.60,1.66)$ & $6 \cdot 80$ \\
\hline Hatsu et al. ${ }^{(50)}$ & $0.39(-0.50,1.28)$ & 4.28 \\
\hline Okechukwu et al. ${ }^{(52)}$ & $\rightarrow 2.71(2.47,2.95)$ & 6.52 \\
\hline Dewey et al. ${ }^{(53)}$ & $0.43(0.09,0.78)$ & $6 \cdot 25$ \\
\hline Brewer et al. ${ }^{(15)}$ & $1.77(0.98,2.55)$ & 4.66 \\
\hline Dewey et al. ${ }^{(54)}$ & $0.37(0.02,0.72)$ & $6 \cdot 24$ \\
\hline Dewey et al. ${ }^{(54)}$ & $0.12(-0.24,0.49)$ & $6 \cdot 19$ \\
\hline Kac et al. ${ }^{(55)}$ & $0.58(0.12,1.04)$ & 5.88 \\
\hline Wosje et al. ${ }^{(56)}$ & $1.00(0.54,1.46)$ & 5.88 \\
\hline Dujmovic et al. ${ }^{(57)}$ & $1.01(0.68,1.34)$ & $6 \cdot 29$ \\
\hline Subtotal $\left(I^{2}=96.7 \%, P=0.000\right)$ & $0.96(0.53,1.40$ & $71 \cdot 17$ \\
\hline$\underline{\mathrm{MF}}$ & & \\
\hline$\overline{\text { Butte et al. }}{ }^{(48)}$ & $0.09(-0.40,0.58)$ & $5 \cdot 77$ \\
\hline Krause et al. ${ }^{(50)}$ & $0.83(0.81,0.86)$ & $6 \cdot 80$ \\
\hline Krause et al. ${ }^{(50)}$ & $1.68(0.94,2.42)$ & $4 \cdot 82$ \\
\hline Brewer et al. ${ }^{(15)}$ & $1.02(0.31,1.74)$ & 4.93 \\
\hline Kac et al. (55) $^{-1}$ & $-0.23(-0.48,0.02)$ & 6.51 \\
\hline Subtotal $\left(I^{2}=99.2 \%, P=0.000\right)$ & $0.63(0.01,1.25)$ & $28 \cdot 83$ \\
\hline Overall $\left(I^{2}=99.3 \%, P=0.000\right)$ & $0.87(0.57,1.17)$ & $100 \cdot 00$ \\
\hline NOTE: Weight are from random-effects analysis & & \\
\hline L & + & \\
\hline-2.95 & 2.95 & \\
\hline SMD & & \\
\hline
\end{tabular}

Fig. 2 Estimates for the standardized mean difference (SMD) of breast-feeding (EBF, exclusive breast-feeding; MF, mixed breastfeeding) $v$. formula-feeding on weight loss at 3-6 months postpartum. Study-specific SMD estimates are represented by grey squares, where the size of the square reflects the study-specific statistical weight (i.e. inverse of the variance), and their $95 \% \mathrm{Cl}$ are represented by horizontal lines. The centre of the diamond presents the pooled SMD and its width represents the pooled $95 \% \mathrm{Cl}$. Dewey et al. ${ }^{(54)}$ provided two results, one for primiparous mothers (effect size for primiparous mothers $=1$ ) and one for mothers of low-birth-weight infants (effect size for mothers of low-birth-weight infants =2) 
Table 2 Sensitivity analyses of studies included in the meta-analysis of breast-feeding on postpartum weight retention

\begin{tabular}{|c|c|c|c|}
\hline Component & No. of studies & Pooled SMD & $95 \% \mathrm{Cl}$ \\
\hline \multicolumn{4}{|l|}{ Study type } \\
\hline RCT & 3 & 0.57 & $0.19,0.94$ \\
\hline Cohort study & 8 & 1.18 & $0.74,1.62$ \\
\hline \multicolumn{4}{|l|}{ Quality of studies } \\
\hline$\geq 5$ points & 10 & $1 \cdot 10$ & $0.55,1.53$ \\
\hline$<5$ points & 1 & 0.71 & $0.45,0.97$ \\
\hline \multicolumn{4}{|c|}{ No. of confounding factors adjusted for } \\
\hline$<6$ & 5 & 0.86 & $0.76,0.94$ \\
\hline$\geq 6$ & 6 & $1 \cdot 13$ & $1.60,1.65$ \\
\hline \multicolumn{4}{|l|}{ Study population } \\
\hline Americans & 7 & 0.79 & $0.19,1.38$ \\
\hline Non-Americans & 4 & 1.27 & $0.37,2 \cdot 17$ \\
\hline
\end{tabular}

SMD, standardized mean difference; RCT, randomized controlled trial.

one in Brazil, one in France, one in Georgia and one in Croatia. The aim of the current systematic review and meta-analysis was to examine the evidence to date regarding the role of $\mathrm{BF}$ in PPWR. The available evidence held belief that $\mathrm{BF}$ decreases PPWR. The fact that we found an association between BF and PPWR at 6 months and not at 3 months postpartum may indicate that certain BF duration is necessary for the maximal effect to be observed. Lof and Forsum ${ }^{(58)}$ showed that expansion of plasma volume during pregnancy can persist during at least the first month postpartum. They measured body water in healthy women before, during and after pregnancy and reported an average of $2 \mathrm{~kg}$ of fluid remaining at 2 weeks postpartum.

In theory, weight change is supported by negative energy balance due to either increased energy expenditure or reduced energy intake, or both. Although postpartum lactation increases energy expenditure significantly due to the production of milk in the mammary glands ${ }^{(9)}$, it is also accompanied by increased energy intake $^{(53)}$, so PPWR cannot be explained merely by changes in energy expenditure or energy intake alone. Thus, we speculate that postpartum weight change may relate mainly to hormonal/metabolic changes induced by lactation. Indeed, after parturition, withdrawal of progesterone and the suckling of the breast by the infant facilitate the release of prolactin, thereby decreasing the level of oestrogen $^{(9)}$, which in turn enhances the mobilization of adipose tissue stores ${ }^{(59)}$. Furthermore, since prolactin also inhibits lipogenesis ${ }^{(60)}$ and suppresses glucose uptake in adipose tissue ${ }^{(61)}$, it is conceivable that the pregnancyinduced pattern of fat deposition may be reversed during lactation by the fluctuating hormones.

Although the majority of the studies included in the systematic review found significant associations between $\mathrm{BF}$ and PPWR, or significant differences in weight change between $\mathrm{BF}$ and FF women, it is difficult to make any firm conclusions, as many of the associations observed depended on the time at which the postpartum measurements were carried out. Among the studies that did show a positive influence of $\mathrm{BF}$ on weight loss, the associations tended to be relatively weak and were often confounded by other factors, such as GWG, physical activity and prepregnancy weight. Associations also appeared to be dependent on the duration and intensity of BF.

It appeared that for the majority of studies, BF for $<3$ months had little or no influence on weight change, whereas there was some evidence to suggest that BF, if continued for $>6$ months, may have a positive influence on weight change; but again this was not supported by all of the studies and in many of them the associations were only observed in women who continued $\mathrm{BF}$ until 12 months postpartum. However, our meta-analysis showed that compared with FF, BF for 3-6 months seemed to have a positive influence on weight change, and if $\mathrm{BF}$ continued for $>6$ months may have little or no influence on weight change. These differences may be due to the intensity and duration of $\mathrm{BF}$, the population under study (source, size, location, loss to follow-up), how weight and weight retention were assessed, how BF was assessed and statistical methods. Nevertheless, the review provides a valuable insight into the studies to date and the findings should be useful in guiding the development of future studies.

In relation to definition of $\mathrm{BF}$, it appeared that the assessment of exposure to BF differed from study to study: most of the studies compared women who breast-fed their infants with women who formula-fed infants, while a few studies compared women who have lactation with women who have non-lactation (Table 1). However, in a sensitivity analysis, homogeneity between the studies stratified by different definitions of feeding could not be rejected (Table 2).

On the other hand, there are a number of known predictors for PPWR, such as GWG ${ }^{(16)}$, pre-pregnancy weight, physical activity and other lifestyle factors ${ }^{(17)}$. Because we cannot exclude residual confounding, so we could not draw any confirm conclusions regarding the role of $\mathrm{BF}$ in weight change. The effect of BF might not be a genuine risk factor for PPWR but rather reflect a common cause for PPWR. 
Irrespective of the underlying mechanisms, these data suggest that BF may help to reduce PPWR. A potentially beneficial effect of BF on PPWR needs to be balanced against other risks of PPWR. As pre-pregnancy weight and GWG were frequently cited as strong contributing factors to PPWR, observational studies should commence preconception with continued monitoring into the postpartum period, to capture the true trajectory of weight change.

\section{Strengths and limitations}

The possibility that BF may assist women in minimizing weight retention after pregnancy has long been controversial. Thus, a systematic review and meta-analysis was performed to examine the effect estimate of $\mathrm{BF}$ on PPWR. Broad search terms and multiple bibliographic databases were used in the searches to capture as many relevant papers as possible, and a robust systematic approach was used to select the final papers. To disentangle the effect of BF on PPWR, we studied both BF and FF postpartum. On the basis of results of our metaanalysis, we propose to use the term 'PPWR' only for weight retention within a limited postpartum period, for example up to 6 months or 9 months postpartum. However, because of the limitation of the data, the conclusion should be considered with caution. A large and welldesigned study that addresses various patterns of $\mathrm{BF}$ in separate analysis by precise definitions of $\mathrm{BF}$ is warranted and several additional measurements, for example until 12 months or 24 months postpartum, would be necessary to provide any definitive findings.

In addition, a classical meta-analysis requires RCT. Randomization of BF on an individual level is not ethical, however. Unfortunately, there are no cluster-randomized controlled trials on $\mathrm{BF}$ and weight change in the literature.

\section{Conclusions}

Our meta-analysis showed that compared with $\mathrm{FF}$, BF for 3 to $\leq 6$ months seemed to have a negative influence on PPWR; however, BF continued for $>6$ months may have little or no influence on PPWR. As we cannot exclude residual confounding, it is difficult to draw any firm conclusions. More robust studies are needed to reliably assess the impact of patterns and duration of BF on postpartum weight retention.

\section{Acknowledgements}

Financial support: This work was supported by the National Natural Science Foundation of China (grant number 81373011). The National Natural Science Foundation of China had no role in the design, analysis or writing of this article. Conflicts of interest: None.
Authorship: X.H. and M.Z. contributed equally to this work and should be considered co-first authors. X.H. and M.Z. contributed to the literature review, meta-analysis and principal authorship of the article; X.T., Y. Li and Q.W. contributed to conception of the research question, literature review, data extraction and final draft of the manuscript; C.H. contributed to the first and final drafts of the manuscript; Y. Liu reviewed the grammar of the manuscript. Ethics of buman subject participation: Ethical approval was not required.

\section{Supplementary material}

To view supplementary material for this article, please visit http://dx.doi.org/10.1017/S1368980015000828

\section{References}

1. Krummel DA (2007) Postpartum weight control: a vicious cycle. J Am Diet Assoc 107, 37-40.

2. Lovelady C (2011) Balancing exercise and food intake with lactation to promote postpartum weight loss. Proc Nutr SoC 70, 181-184.

3. Gunderson EP, Abrams B \& Selvin S (2001) Does the pattern of postpartum weight change differ according to pregravid body size? Int J Obes Relat Metab Disord 25, 853-862.

4. Williamson DF, Madans J, Pamuk E et al. (1994) A prospective study of childbearing and 10-year weight gain in US white women 25 to 45 years of age. Int J Obes Relat Metab Disord 18, 561-569.

5. Rooney BL \& Schauberger CW (2002) Excess pregnancy weight gain and long-term obesity: one decade later. Obstet Gynecol 100, 245-252.

6. Linne Y \& Neovius M (2006) Identification of women at risk of adverse weight development following pregnancy. Int J Obes (Lond) 30, 1234-1239.

7. Ip S, Chung M, Raman G et al. (2007) Breastfeeding and maternal and infant health outcomes in developed countries. Evid Rep Technol Assess (Full Rep) issue 153, 181-186.

8. Schwarz EB, Ray RM, Stuebe AM et al. (2009) Duration of lactation and risk factors for maternal cardiovascular disease. Obstet Gynecol 113, 974-982.

9. Butte NF \& Hopkinson JM (1998) Body composition changes during lactation are highly variable among women. J Nutr 128, 2 Suppl., 381S-385S.

10. Shrewsbury VA, Robb KA, Power C et al. (2009) Socioeconomic differences in weight retention, weight-related attitudes and practices in postpartum women. Matern Child Health J 13, 231-240.

11. Parker JD \& Abrams B (1993) Differences in postpartum weight retention between black and white mothers. Obstet Gynecol 81, 768-774.

12. Boardley DJ, Sargent RG, Coker AL et al. (1995) The relationship between diet, activity, and other factors, and postpartum weight change by race. Obstet Gynecol 86, 834-838.

13. Potter S, Hannum S, McFarlin B et al. (1991) Does infant feeding method influence maternal postpartum weight loss? J Am Diet Assoc 91, 441-446.

14. Zanartu D, Polan CE, Ferreri LE et al. (1983) Effect of stage of lactation and varying available energy intake on milk production, milk composition, and subsequent tissue enzymic activity. J Dairy Sci 66, 1644-1652. 
15. Brewer MM, Bates MR \& Vannoy LP (1989) Postpartum changes in maternal weight and body fat depots in lactating vs nonlactating women. Am J Clin Nutr 49, 259-265.

16. Gunderson EP, Abrams B \& Selvin S (2000) The relative importance of gestational gain and maternal characteristics associated with the risk of becoming overweight after pregnancy. Int $J$ Obes Relat Metab Disord 24 , 1660-1668

17. Walker LO, Timmerman GM, Sterling BS et al. (2004) Do low-income women attain their pre-pregnant weight by the 6th week of postpartum? Ethn Dis 14, 119-126.

18. Oken E, Taveras EM, Popoola FA et al. (2007) Television, walking, and diet: associations with postpartum weight retention. Am I Prev Med 32, 305-311.

19. Baker JL, Gamborg M, Heitmann BL et al. (2008) Breastfeeding reduces postpartum weight retention. Am J Clin Nutr 88, 1543-1551.

20. Mok E, Multon C, Piguel L et al. (2008) Decreased full breastfeeding, altered practices, perceptions, and infant weight change of prepregnant obese women: a need for extra support. Pediatrics 121, e1319-e1324.

21. Lovelady CA, Garner KE, Moreno KL et al. (2000) The effect of weight loss in overweight, lactating women on the growth of their infants. $N$ Engl J Med 342, 449-453.

22. Mulder PJ, Johnson TS \& Baker LC (2010) Excessive weight loss in breastfed infants during the postpartum hospitalization. J Obstet Gynecol Neonatal Nurs 39, 15-26.

23. Valeggia CR \& Ellison PT (2003) Impact of breastfeeding on anthropometric changes in peri-urban Toba women (Argentina). Am J Hum Biol 15, 717-724.

24. Sichieri R, Field AE, Rich-Edwards J et al. (2003) Prospective assessment of exclusive breastfeeding in relation to weight change in women. Int I Obes Relat Metab Disord 27, 815-820.

25. Sarkar NR \& Taylor R (2005) Weight loss during prolonged lactation in rural Bangladeshi mothers. J Health Popul Nutr 23, 177-183.

26. Preer GL, Newby PK \& Philipp BL (2012) Weight loss in exclusively breastfed infants delivered by cesarean birth. I Hum Lact 28, 153-158.

27. Dugdale AE \& Eaton-Evans J (1989) The effect of lactation and other factors on post-partum changes in body-weight and triceps skinfold thickness. Br J Nutr 61, 149-153.

28. Walker LO \& Freeland-Graves J (1998) Lifestyle factors related to postpartum weight gain and body image in bottleand breastfeeding women. J Obstet Gynecol Neonatal Nurs 27, 151-151

29. Barbosa L, Butte NF, Villalpando S et al. (1997) Maternal energy balance and lactation performance of Mesoamerindians as a function of body mass index. Am J Clin Nutr 66, 575-583

30. Caire-Juvera G, Casanueva E, Bolanos-Villar AV et al. (2012) No changes in weight and body fat in lactating adolescent and adult women from Mexico. Am J Hum Biol 24 , 425-431.

31. Juni P, Altman DG \& Egger M (2001) Systematic reviews in health care: assessing the quality of controlled clinical trials. BMJ 323, 42-46.

32. DerSimonian R \& Laird N (1986) Meta-analysis in clinical trials. Control Clin Trials 7, 177-188.

33. Higgins JP, Thompson SG, Deeks JJ et al. (2003) Measuring inconsistency in meta-analyses. BMJ 327, 557-560.

34. Woolf B (1955) On estimating the relation between blood group and disease. Ann Hum Genet 19, 251-253.

35. Egger M, Davey Smith G, Schneider M et al. (1997) Bias in meta-analysis detected by a simple, graphical test. BMJ 315 629-634.

36. Begg CB \& Mazumdar M (1994) Operating characteristics of a rank correlation test for publication bias. Biometrics $\mathbf{5 0}$ 1088-1101
37. da Silva MD, Oliveira Assis AM, Pinheiro SM et al. (2013) Breastfeeding and maternal weight changes during 24 months post-partum: a cohort study. Matern Child Nutr (Epublication ahead of print version).

38. Murnane PM, Arpadi SM, Sinkala M et al. (2010) Lactationassociated postpartum weight changes among HIV-infected women in Zambia. Int J Epidemiol 39, 1299-1310.

39. Cohen SS, Larson CO, Matthews CE et al. (2009) Parity and breastfeeding in relation to obesity among black and white women in the southern community cohort study. J Womens Health (Larchmt) 18, 1323-1332.

40. Janney CA, Zhang D \& Sowers M (1997) Lactation and weight retention. Am J Clin Nutr 66, 1116-1124.

41. AbuSabha R \& Greene G (1998) Body weight, body composition, and energy intake changes in breastfeeding mothers. J Hum Lact 14, 119-124.

42. Gigante DP, Victora CG \& Barros FC (2001) Breast-feeding has a limited long-term effect on anthropometry and body composition of Brazilian mothers. J Nutr 131, 78-84.

43. Quandt SA (1983) Changes in maternal postpartum adiposity and infant feeding patterns. Am J Phys Anthropol 60, 455-461.

44. Ota E, Haruna M, Matsuzaki M et al. (2008) Comparison of body fat mass changes during the third trimester and at one month postpartum between lactating and nonlactating Japanese women. Biosci Trends 2, 200-205.

45. Nommsen-Rivers LA, Chantry CJ, Peerson JM et al. (2010) Delayed onset of lactogenesis among first-time mothers is related to maternal obesity and factors associated with ineffective breastfeeding. Am J Clin Nutr 92, 574-584.

46. Brandhagen M, Lissner L, Brantsaeter AL et al. (2014) Breast-feeding in relation to weight retention up to 36 months postpartum in the Norwegian Mother and Child Cohort Study: modification by socio-economic status? Public Health Nutr 17, 1514-1523.

47. Ostbye T, Peterson BL, Krause KM et al. (2012) Predictors of postpartum weight change among overweight and obese women: results from the Active Mothers Postpartum study. I Womens Health (Larchmt) 21, 215-222.

48. Butte NF, Hopkinson JM, Mehta N et al. (1999) Adjustments in energy expenditure and substrate utilization during late pregnancy and lactation. Am J Clin Nutr 69, 299-307.

49. Ly CT, Diallo A, Simondon F et al. (2006) Early short-term infant food supplementation, maternal weight loss and duration of breast-feeding: a randomised controlled trial in rural Senegal. Eur J Clin Nutr 60, 265-271.

50. Krause KM, Lovelady CA, Peterson BL et al. (2010) Effect of breast-feeding on weight retention at 3 and 6 months postpartum: data from the North Carolina WIC Programme. Public Health Nutr 13, 2019-2026.

51. Hatsu IE, McDougald DM \& Anderson AK (2008) Effect of infant feeding on maternal body composition. Int Breastfeed J 3, 18.

52. Okechukwu AA, Okpe EC \& Okolo AA (2009) Exclusive breastfeeding and postnatal changes in maternal anthropometry. Niger J Clin Pract 12, 383-388.

53. Dewey KG, Heinig MJ \& Nommsen LA (1993) Maternal weight-loss patterns during prolonged lactation. Am J Clin Nutr 58, 162-166.

54. Dewey KG, Cohen RJ, Brown KH et al. (2001) Effects of exclusive breastfeeding for four versus six months on maternal nutritional status and infant motor development: results of two randomized trials in Honduras. $J$ Nutr 131, 262-267.

55. Kac G, Benicio MH, Velasquez-Melendez G et al. (2004) Breastfeeding and postpartum weight retention in a cohort of Brazilian women. Am J Clin Nutr 79, 487-493.

56. Wosje KS \& Kalkwarf HJ (2004) Lactation, weaning, and calcium supplementation: effects on body composition in postpartum women. Am J Clin Nutr 80, 423-429. 
57. Dujmović M, Kresić G, Mandić ML et al. (2014) Changes in dietary intake and body weight in lactating and nonlactating women: prospective study in Northern Coastal Croatia. Coll Antropol 38, 179-187.

58. Lof M \& Forsum E (2004) Evaluation of bioimpedance spectroscopy for measurements of body water distribution in healthy women before, during, and after pregnancy. J Appl Physiol (1985) 96, 967-973.
59. Pansini F, Bonaccorsi G, Genovesi F et al. (1990) Influence of estrogens on serum free fatty acid levels in women. J Clin Endocrinol Metab 71, 1387-1389.

60. Ben-Jonathan N, Hugo ER, Brandebourg TD et al. (2006) Focus on prolactin as a metabolic hormone. Trends Endocrinol Metab 17, 110-116.

61. Nilsson LA, Roepstorff C, Kiens B et al. (2009) Prolactin suppresses malonyl-CoA concentration in human adipose tissue. Horm Metab Res 41, 747-751. 